\title{
COMUNICAÇÃO
}

\section{EFEITO DAS FORMAS DE APRESENTAÇÃO DO MILHO E DO USO DE PEDRISCO NA RAÇÃO, SOBRE O DESEMPENHO DE FRANGO DE CORTE ${ }^{1}$}

\author{
VEREDINO LOUZADA DA SILVA JÚNIOR ${ }^{2}$ \\ JUDAS TADEU DE BARROS COTTA ${ }^{3}$ \\ ANTÔNIO ILSON GOMES DE OLIVEIRA ${ }^{4}$
}

\begin{abstract}
RESUMO - Para avaliar a influência das formas de apresentação do milho e a presença de pedrisco granítico sobre o desempenho em frangos de corte, utilizaram-se 720 frangos com 22 dias de idade, de ambos os sexos, submetidos aos tratamentos: forma de apresentação do milho (inteiro, moído grosso e moído fino), pedrisco (ausência e presença) e sexo (macho e fêmea). O experimento foi conduzido em um delineamento inteiramente casualizado (DIC) em esquema fatorial $3 \times 2$ × 2 (formas de apresentação do milho, sem e com pedrisco e sexo), com quatro repetições de quinze aves em cada uma. Para avaliar o desempenho das aves em 3 períodos consecutivos (22 a 28, 29 a 35 e 36 a 42 dias), esses períodos foram considerados como subparcelas. No período de 22 a 42 dias, os frangos
\end{abstract}

que receberam pedrisco aumentaram $(\mathrm{P}<0,05)$ o consumo da ração com milho moído fino em relação aos que não o receberam. Entretanto, o pedrisco não influenciou no consumo das aves alimentadas com rações de milho inteiro ou milho moído grosso. Não foi observado efeito do pedrisco $(\mathrm{P}>0,05)$ com relação às demais variáveis do desempenho. Aparentemente, o fornecimento do pedrisco não apresenta vantagens, já que não beneficia o desempenho. O ganho de peso e a conversão alimentar apresentaram as melhores $(\mathrm{P}<0,05)$ médias em aves que se alimentaram com dietas de milho moído (grosso ou fino). Conclui-se que é viável o uso do milho moído grosso na alimentação de frangos de corte a partir de 21 dias de idade. $\mathrm{O}$ milho inteiro piora o desempenho.

TERMOS PARA INDEXAÇÃO: Desempenho, frango de corte, milho inteiro, milho moído, pedrisco granítico.

\section{EFFECT OF THE FORMS OF PRESENTATION OF CORN AND THE USE OF GRIT IN THE RATIONS ON PERFORMANCE IN BROILER}

\begin{abstract}
In order to evaluate the influence of the forms of presentation of corn and the presence of granitic grit on the performance of broiler, 720 broiler 22 days old from both sexes were used. The treatments employed were: form of presentation of corn (whole, gross and fine ground), grit (absence and presence) and sex (male and female). The experimental design was an completely randomized in factorial scheme $3 \times 2 \times 2$ (form of presentation of corn, without and with grit and sex), with four replicates and fifteen birds in each. To
\end{abstract}

evaluate the performance in 3 consecutive periods (22 to 28,29 to 35 and 36 to 42 days), those periods were considered as subplots. In the period from 22 to 42 days, the broilers that were given grit increased $(\mathrm{P}<0,05)$ the ration consumption with fine ground corn in relation to the ones which were not given it. However, grit did not influence the consumption of the birds fed rations of whole or gross ground corn. No effect of the grit was observed $(\mathrm{P}>0,05)$ with relation to the other variables of performance. Apparently, the

1. Dissertação apresentada ao Departamento de Zootecnia da UNIVERSIDADE FEDERAL DE LAVRAS/UFLA, Caixa Postal 37 - 37200-000 - Lavras, MG, pelo primeiro autor, para obtenção do título de Mestre em Zootecnia, na área de Produção Animal/Aves.

2. Mestrando em Zootecnia do DZO/UFLA

3. Professor do Departamento de Zootecnia/UFLA.

4. Professor Titular Aposentado da UFLA. 
supply of grit does not present any advantage, since it does not benefit either performance. Weight gain and feed conversion presented the highest $(\mathrm{P}<0,05)$ means in birds fed diets of corn ground (gross or fine). It follows that the use of the gross ground corn in the feeding of broilers from 21 days of age is feasible. Whole corn worsens performance.

INDEX TERMS: Broiler, grit granitic, ground corn, perfornance, whole corn.

O milho é comumente utilizado moído na ração, assim como os demais ingredientes. Utilizando-se uma moagem mais grossa desse ingrediente, é possível obter maior rendimento do triturador, podendo-se reduzir, com isso, o gasto com a energia elétrica. A economia de energia elétrica seria ainda maior com o uso do grão de milho inteiro na ração, a partir do $21^{\circ}$ dia de idade das aves.

Avaliando o consumo de ração em frango de corte de diferentes idades em função da granulometria, concluiu-se que o consumo de partículas com DGM $>1.180 \mu \mathrm{m}$ foi observado em todas as idades; porém, quando os frangos ficaram mais velhos, o consumo se elevou com partículas de DGM $>2.360 \mu \mathrm{m}$ (PORTELLA et al., 1988). Para Zanotto et al. (1995), as aves têm tendência a consumir, seletivamente, as partículas maiores dos ingredientes das rações. Nir et al. (1990) sugeriram que a preferência pelo tamanho da partícula possa estar relacionada à dimensão do bico e não à composição química do alimento. Ração única com grãos inteiros de milho ou parcialmente triturados não alteram significativamente o desempenho de frangos, aos 42 dias (FREITAS, 2001). Reece et al. (1986) observaram não haver nenhuma diferença no ganho de peso e conversão alimentar de frangos, quando o milho foi moído fino $(3.180 \mu \mathrm{m})$ ou grosso $(9.530 \mu \mathrm{m})$.

Por outro lado, a granulometria mais grossa do milho numa ração passaria a exigir uma maior atividade da moela, já que esse órgão desempenha a mesma função dos dentes dos mamíferos e transforma os ingredientes das rações numa pasta semilíquida. Possivelmente, essa atividade poderia ser facilitada pelo fornecimento de um agente abrasivo. A influência do pedrisco sobre a digestibilidade foi maior, quando se usou alimento moído grosso em vez de moído fino (FRITZ, 1937). Isso ocorre devido à maior secreção gástrica (FRITZ et al., 1936). Quando o pedrisco foi fornecido para aves que se alimentavam de dietas com milho inteiro, ocorreu uma eficiência alimentar superior em $12,5 \%$ e um ganho de peso maior em 16,5\% (BALLOUN, 1959, citado por BRANION e HEUSER, 1960). Entretanto, em um outro trabalho, nenhuma influência significativa do efeito do pedrisco sobre o ganho de peso e eficiência alimentar em aves alimentadas com milho inteiro ou mo- ído fino foi observada (KENNARD e CHAMBERLIN, 1959; MCINTOSH et al., 1962). Trabalhos de pesquisa têm mostrado que é possível aumentar a granulometria do milho e melhorar o desempenho dos frangos com maior economia. Portanto, objetivou-se, com esta pesquisa, verificar a influência da forma de apresentação do milho na ausência ou presença de pedrisco fornecido de livre escolha sobre o desempenho em frangos de corte.

Foram utilizados 720 frangos de corte da linhagem Ross. O período experimental foi do $22^{\circ}$ ao $42^{\circ}$ dia de idade das aves. Foram utilizados 24 boxes para cada sexo, com unidade experimental de 15 aves. O consumo foi medido semanalmente pela diferença entre o que foi fornecido no início da semana, menos a sobra do final da semana. O pedrisco de origem granítica é obtido pelo peneiramento de pó de pedra, com peneira de $4 \mathrm{~mm}$ na malha. Esse material foi colocado num recipiente de plástico afixado à tela dos boxes. As dietas experimentais foram formuladas com milho inteiro ou moído grosso e fino. Na moagem do milho nas granulometrias grossas e finas, empregaram-se peneiras com abertura de $4 \mathrm{~mm}$ e $2 \mathrm{~mm}$, respectivamente, num moinho de martelo. Os tratamentos empregados no experimento, para ambos os sexos, foram a combinação de: ração com milho inteiro, com milho moído grosso e com milho moído fino, presença ou ausência de pedrisco e sexo (machos e fêmeas). As rações experimentais tiveram a mesma composição (Tabela 1), formuladas à base de milho e farelo de soja, sendo balanceadas segundo Rostagno et al. (2000). Entretanto, os valores dos nutrientes foram reajustados para níveis de 2.941 e $3.033 \mathrm{Kcal} / \mathrm{kg}$ de EM para as rações préexperimentais e experimentais, respectivamente. Para calcular o diâmetro geométrico médio (DGM), o desvio padrão geométrico (DPG) da ração e do pedrisco, utilizou-se o programa "PROSUAVI" (CNPSA/EMBRAPA), em que o milho inteiro apresentou DGM de 6,649 $\mu \mathrm{m}$ e DPG de 1,17; o moído grosso DGM de $1,085 \mu \mathrm{m}$ e DPG 2,48; o moído fino DGM de $706 \mu \mathrm{m}$ e DPG de 2,28; e o pedrisco, DGM de $2,246 \mu \mathrm{m}$ e DPG de 1,53 . 
TABELA 1 - Composição percentual e valores nutricionais calculados da ração experimental (22 a 42 dias).

\begin{tabular}{lc}
\hline \multicolumn{1}{c}{ Ingredientes \% } & 22 a 42 dias \\
\hline Milho & 65,69 \\
Farelo de soja & 29,30 \\
Óleo vegetal & 1,76 \\
Fosfato bicálcio & 1,40 \\
Calcário & 1,05 \\
DL- metionina 99 & 0,15 \\
Sal & 0,40 \\
Suplemento vitamínico & 0,10 \\
Suplemento mineral & \\
Anticoccidiano & \\
\hline Total - - - - - - - - - - & 100 \\
\hline EM (kcal/kg) & 3033 \\
Proteína bruta (\%) & 19,12 \\
Metionina (\%) & 0,451 \\
Metionina + cistina (\%) & 0,764 \\
Lisina (\%) & 0,978 \\
Fósforo total (\%) & 0,57 \\
Fósforo disponível (\%) & 0,367 \\
Cálcio (\%) & 0,863 \\
Sódio (\%) & 0,198 \\
\hline - & 13,000 \\
\hline
\end{tabular}

${ }^{1}$ Enriquecimento/kg ração: Vit. A 13.000 UI; Vit. $D_{3} 2.200$ UI; Vit. E 30 mg; Vit. $K_{3} 2,5$ mg; Vit. $B_{1}$ 2,2 mg; Vit. $B_{2} 6 \mathrm{mg}$; Vit. $B_{6} 3,2 \mathrm{mg}$; Vit. $B_{12} 12 \mu \mathrm{g}$; Biotina $110 \mathrm{mcg}$; Niacina $30 \mathrm{mcg}$; Ácido fólico 1 mg; Nicotinamida $53 \mathrm{mg}$; Pantotenato de Ca 12,5 mg; Manganês $130 \mathrm{mg}$; Zinco $100 \mathrm{mg}$; Ferro $80 \mathrm{mg}$; Cobre $24 \mathrm{mg}$; Iodo 2 mg; Selênio 0,2 mg

2 Salinomicina $15 \%$.

As variáveis estudadas foram o consumo de ração, o ganho de peso e a conversão alimentar. O delineamento utilizado foi um DIC em esquema fatorial $3 \times 2$ x 2 (forma de apresentação do milho, ausência ou presença de pedrisco e sexo) com quatro repetições constituída por quinze aves cada uma. Para avaliar o desempenho das aves em três períodos consecutivos (22 a 28 , 29 a 35 e 36 a 42 dias), esses períodos foram considerados como subparcelas.
Para a análise de variância, utilizou-se o pacote computacional no SISVAR, versão 4,3 descrito por Ferreira (2000). As médias dos tratamentos foram comparadas pelo teste de Scott-Knott a $5 \%$ de probabilidade.

Os resultados de consumo de ração (CR), ganho de peso (GP) e conversão alimentar (CA), segundo os tratamentos no período de 22 a 42 dias de idade, são apresentados na Tabela 2. Ocorreu interação $(\mathrm{P}<0,05)$ entre a forma de apresentação do milho e o pedrisco para o consumo, que foi desdobrada na Tabela 3. As aves alimentadas com ração de milho inteiro apresentaram piores $(\mathrm{P}<0,05)$ ganhos de peso e conversão alimentar. Machos consumiram mais ração, ganharam mais peso e tiveram melhor conversão alimentar que as fêmeas.

Pela Tabela 3 constata-se uma interação $(\mathrm{P}<0,01)$ entre a forma de apresentação do milho e o pedrisco.

$\mathrm{Na}$ ausência do pedrisco, as aves alimentadas com ração com milho moído fino apresentaram menor $(\mathrm{P}<0,05)$ consumo que as aves alimentadas com rações contendo milho inteiro ou moído grosso, ao passo que, na presença de pedrisco, não houve diferença entre os consumos. $\mathrm{O}$ aumento no consumo de ração contendo milho moído fino nas aves alimentadas com pedrisco em relação àquelas alimentadas com essa dieta sem pedrisco não encontra suporte na literatura, uma vez que Fritz (1937), por exemplo, afirmam que os benefícios da digestão mecânica são mínimos em alimentos finamente moídos. Por outro lado, Fritz et al. (1936) sugerem que pode ocorrer um aumento na secreção gástrica, o qual poderia estar associado à presença do pedrisco, transformando essa dieta numa pasta semilíquida em menor tempo e aumentando, com isso, o consumo, devido a maior sensação de fome das aves.

As maiores $(\mathrm{P}<0,05)$ médias de GP apresentadas pelas aves que receberam ração com milho moído (grosso ou fino) no período total (22 a 42 dias) em relação àquelas que receberam ração de milho inteiro (Tabela 2) podem ser atribuídas ao menor $(\mathrm{P}<0,05)$ ganho de peso das aves com dieta de milho inteiro no período inicial de 22 a 28 dias na Tabela 4. Resultados semelhantes ao período de 22 a 42 dias foram encontrados por Reece et al. (1986), ao estudarem o efeito do milho moído, fino $(3.180 \mu \mathrm{m})$ ou grosso $(9.530 \mu \mathrm{m})$ sobre o ganho de peso de frangos de corte.

Semelhantemente ao ganho de peso, a pior CA para aves alimentadas com milho inteiro é reflexo do baixo desempenho no período inicial de 22 a 28 dias de idade na Tabela 4. 
TABELA 2 - Consumo de ração $(\mathrm{g})$, ganho de peso (g) e conversão alimentar, segundo a forma de apresentação do milho na ração, o pedrisco e o sexo do período de 22 a 42 dias de idade*.

\begin{tabular}{lccc}
\hline \multicolumn{1}{c}{ Fatores } & CR*** & GP & CA \\
\hline Forma de apresentação do milho & & & $1,99 \mathrm{~b}$ \\
Inteiro & 3.033 & $1.525 \mathrm{~b}$ & $1,88 \mathrm{a}$ \\
Moído grosso & 3.026 & $1.609 \mathrm{a}$ & $1,87 \mathrm{a}$ \\
Moído fino & 2.957 & $1.583 \mathrm{a}$ & 1,92 \\
Pedrisco & & & 1,92 \\
Ausente & 2.988 & 1.564 & $1,88 \mathrm{~A}$ \\
Presente & 3.023 & 1.581 & $1,95 \mathrm{~B}$ \\
Sexo & & & 3,52 \\
Macho & $3.208 \mathrm{~A}$ & $1.707 \mathrm{~A}$ & $1.438 \mathrm{~B}$ \\
Fêmea & $2.803 \mathrm{~B}$ & 4,61 & \\
\hline C.V. $(\%)$ & 2,86 & & \\
\hline
\end{tabular}

*Médias seguidas de letras diferentes nas colunas, minúscula para forma de apresentação do milho e maiúscula para sexo, são desiguais pelo teste de Scott-Knott $(\mathbf{P}<0,05)$.

**Interação forma de apresentação x pedrisco $(\mathbf{P}>0,01)$ (Tabela 3$)$.

TABELA 3 - Consumo (g) de ração no período de 22 a 42 dias, de acordo com a presença ou ausência do pedrisco e a forma de apresentação do milho na ração*.

\begin{tabular}{|c|c|c|c|}
\hline \multirow{2}{*}{ Apresentação do milho } & \multicolumn{2}{|c|}{ Pedrisco } & \multirow{2}{*}{ Médias } \\
\hline & Ausente & Presente & \\
\hline Inteiro & $3.003 \mathrm{a} \mathrm{A}$ & $3.063 \mathrm{a} \mathrm{A}$ & 3.033 \\
\hline Moído grosso & $3.056 \mathrm{a} \mathrm{A}$ & 2.996 a A & 3.026 \\
\hline Moído fino & 2.904 b B & $3.009 \mathrm{a} \mathrm{A}$ & 2.957 \\
\hline Médias & 2.988 & 3.023 & \\
\hline C.V. $(\%)$ & & & \\
\hline
\end{tabular}

*Médias seguidas de letras distintas, maiúsculas nas linhas e minúsculas nas colunas, diferem entre si pelo teste de Scott-Knott $(\mathbf{P}<0,05)$.

Os machos mostraram-se mais eficientes $(\mathrm{P}<0,05)$ que as fêmeas, de 22 a 42 dias, o que é natural, tendo em vista o maior ganho de peso dos machos. É válido ressaltar que, de forma geral, as médias de CA para ambos os sexos estão compatíveis com as médias para a linhagem AgRoss 308.

É possível constatar pela análise do consumo e do ganho de peso médio nos diferentes períodos (Tabela 4) que, de 22 a 28 dias, as aves que receberam ração com milho moído grosso apresentaram maior $(\mathrm{P}<0,05)$ consumo, o qual poderia ser atribuído ao fato de o milho moído grosso ser mais atrativo por apresentar o diâmetro geométrico médio maior do que o milho moído fino. Resultados semelhantes foram encontrados por Freitas (2001), ao estudar o efeito de ração em diferentes formas de apresentação do milho sobre o consumo de ração por frangos de corte, no período de 22 a 28 dias.

No período seguinte ( 29 a 35 dias), as diferentes formas de apresentação do milho não influenciaram

Ciênc. agrotec., Lavras. V.27, n.5, p.1165-1171, set./out., 2003 
( $P>0,05)$ o consumo de ração, fato esse explicável, tendo em vista o maior desenvolvimento do bico, possibilitando melhor apreensão e ingestão do grão inteiro. Na última semana (36 a 42 dias), as aves apresentaram maior $(\mathrm{P}<0,05)$ consumo de ração de milho inteiro do que ração com milho moído grosso ou fino, o que, segundo Nir et al. (1990) e Portella et al. (1988), se justifica pela preferência que as aves têm por partículas de maior tamanho com o avanço da idade.

Em todos os períodos estudados, o CR não foi influenciado $(\mathrm{P}>0,05)$ pela ausência ou presença do pedrisco, mas, tendo em vista o dimorfismo sexual (machos diferem das fêmeas pelo maior desenvolvimento corporal), o $\mathrm{CR}$ foi maior $(\mathrm{P}<0,05)$ nos machos em todos os períodos avaliados. Segundo o Manual do Frango AgRoss 308, no período de 22 a 42 dias de idade, os machos consomem 3,290 $\mathrm{g}$ e as fêmeas $2,811 \mathrm{~g}$.

Constatou-se uma interação $(\mathrm{P}<0,05)$ entre período e sexo para o ganho de peso (Figura 1), que pode ser explicada pelo fato de os machos apresentaram uma elevação mais acentuada para o ganho de peso, no período de 22 a 28 dias, para o de 29 a 35 dias, em relação às fêmeas.

Em todos os períodos estudados, não houve efeito $(\mathrm{P}>0,05)$ do pedrisco sobre o ganho de peso das aves que receberam rações nas diferentes formas de apresentação do milho.

Os resultados obtidos neste trabalho, no qual os machos apresentaram maior $(\mathrm{P}<0,05)$ GP que as fê- meas, são similares aos esperados para aves da linhagem AgRoss 308, neste período de 22 a 42 dias.

De 22 a 28 dias, os frangos apresentaram melhores $(\mathrm{P}<0,05)$ médias de conversão alimentar (Tabela 5) quando receberam dietas com milho moído (grosso ou fino). A dieta contendo milho inteiro, devido a um desbalanço nutricional, não proporcionou condições para que as aves aproveitassem os nutrientes da mesma, o que levou a uma pior $(\mathrm{P}<0,05) \mathrm{CA}$. Com relação à dieta de milho moído fino, embora essa tenha apresentado menor consumo $(\mathrm{P}<0,05)$ que a dieta com milho moído grosso, a CA foi a mesma.

No período de 29 a 35 dias, não houve efeito $(\mathrm{P}>0,05)$ das rações de milho nas diferentes formas de apresentação sobre a conversão alimentar. Na última semana (36 a 42 dias), as aves que receberam ração com milho moído fino apresentaram melhor $(\mathrm{P}<0,05)$ CA. Isso poderia ser atribuído à maior eficiência alimentar da ave submetida a essa ração nessa fase. Em todos os períodos estudados, não foi observado o efeito $(P>0,05)$ do pedrisco sobre a conversão alimentar. Esses dados assemelham-se aos encontrados por Kennard e Chamberlin (1959) e McIntosh et al. (1962), quando estudaram o efeito de pedrisco granítico, fornecido de livre escolha, sobre a CA em frangos alimentados com dietas de granulometria grossa ou fina.

Nos períodos de 22 a 28,29 a 35 e 36 a 42 dias, não se observou o efeito $(\mathrm{P}>0,05)$ do sexo sobre a CA.

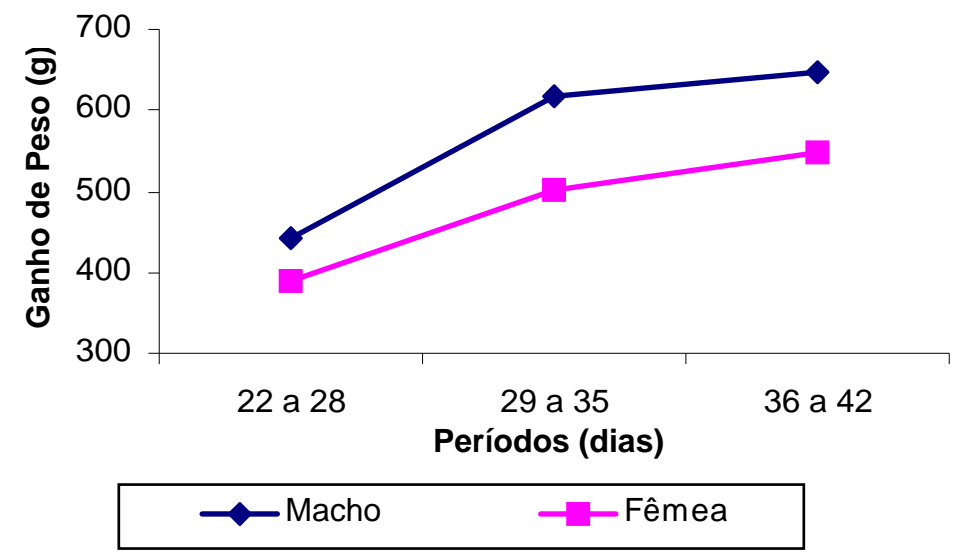

FIGURA 1 - Ganho de peso (g) dos frangos em função do sexo e do período de criação. 
TABELA 4 - Consumo de ração (g) e ganho de peso $(\mathrm{g})$ segundo as formas de apresentação do milho na ração, o pedrisco, o sexo e períodos de criação*.

\begin{tabular}{|c|c|c|c|c|c|c|}
\hline \multirow{2}{*}{ Fatores } & \multicolumn{3}{|c|}{ CR nos períodos } & \multicolumn{3}{|c|}{ GP nos períodos } \\
\hline & 22 a 28 & 29 a 35 & 36 a 42 & 22 a 28 & 29 a 35 & 36 a 42 \\
\hline \multicolumn{7}{|c|}{ Forma de apresentação do milho } \\
\hline Inteiro & $696,85 \mathrm{~b}$ & 1059,61 & $1276,70 \mathrm{a}$ & $370,17 \mathrm{~b}$ & 555,49 & 599,73 \\
\hline Moído grosso & $759,17 \mathrm{a}$ & 1076,19 & $1190,90 \mathrm{~b}$ & $453,54 \mathrm{a}$ & 580,33 & 575,66 \\
\hline Moído fino & $712,08 \mathrm{~b}$ & 1046,73 & $1197,99 \mathrm{~b}$ & $422,50 \mathrm{a}$ & 542,71 & 617,44 \\
\hline \multicolumn{7}{|l|}{ Pedrisco } \\
\hline Ausente & 732,62 & 1046,49 & 1208,77 & 417,61 & 553,96 & 592,54 \\
\hline Presente & 712,78 & 1075,20 & 1234,96 & 413,19 & 565,06 & 602,68 \\
\hline \multicolumn{7}{|l|}{ Sexo } \\
\hline Macho & $759,44 \mathrm{~A}$ & $1148,60 \mathrm{~A}$ & $1299,60 \mathrm{~A}$ & $440,83 \mathrm{~A}$ & $618,37 \mathrm{~A}$ & $647,63 \mathrm{~A}$ \\
\hline Fêmea & $685,95 \mathrm{~B}$ & $973,10 \mathrm{~B}$ & $1144,16 \mathrm{~B}$ & $389,97 \mathrm{~B}$ & $500,64 \mathrm{~B}$ & $547,60 \mathrm{~B}$ \\
\hline C.V. (\%) & & 5,98 & & & 11,12 & \\
\hline
\end{tabular}

*Médias seguidas de letras diferentes nas colunas, minúscula para forma de apresentação do milho e maiúscula para sexo, são desiguais pelo teste de Scott-Knott $(\mathbf{P}<0,05)$.

TABELA 5 - Conversão alimentar, segundo a forma de apresentação do milho na ração, pedrisco, sexos e períodos de criação*.

\begin{tabular}{lccc}
\hline \multicolumn{1}{c}{ Fatores } & \multicolumn{3}{c}{ Períodos (dias) } \\
\cline { 2 - 4 } & $\mathbf{2 2} \mathbf{~ a ~ 2 8}$ & $\mathbf{2 9} \mathbf{a ~ 3 5}$ & $\mathbf{3 6} \mathbf{~} \mathbf{4 2}$ \\
\hline Forma de apresentação do milho & & & $2,15 \mathrm{~b}$ \\
Inteiro & $1,90 \mathrm{~b}$ & 1,92 & $2,11 \mathrm{~b}$ \\
Moído grosso & $1,68 \mathrm{a}$ & 1,86 & 1,96 a \\
Moído fino & $1,69 \mathrm{a}$ & 1,94 & 2,06 \\
Ausente pedrisco & 1,77 & 1,89 & 2,09 \\
Presente pedrisco & 1,75 & 1,92 & 2,05 \\
Macho & 1,75 & 1,87 & 2,10 \\
Fêmea & 1,77 & 1,95 & 11,12 \\
\hline C.V.(\%) & & 1,75 & \\
\hline
\end{tabular}

*Médias seguidas de letras diferentes nas colunas, minúsculas para forma de apresentação do milho e maiúscula para sexo, são desiguais pelo teste de Scott e Knott $(P<0,05)$. 
A partir de 21 dias de idade, o uso de milho grosso na alimentação de frangos de corte não compromete o desempenho. $\mathrm{O}$ milho inteiro prejudica o desempenho.

\section{REFERÊNCIAS BIBLIOGRÁFICAS}

BRANION, H. D.; HEUSER, G. F. Grit for poultry: granite grit Institute of America. New York: INC, 1960.

COTTA, J. T. B. Produção de carne de frango. Lavras: UFLA/FAEPE, 1997. 197 p.

FERREIRA, D. F. Análises estatísticas por meio do Sisvar para Windws: versão 4.0. In: REUNIÃO ANUAL DA REGIÃO BRASILEIRA DA SOCIEDADE INTERNACIONAL DE BIOMETRIA, 45., 2000, São Carlos. Anais... São Carlos: UFSCar, 2000. p. 255-258.

FREITAS, H. J. Alimentação de frangos de corte usando grãos inteiros e moídos de milho em dois sistemas de manejo. 2001. 82 p. Dissertação (Mestrado em Produção Animal) - Universidade Federal de Lavras, Lavras, 2001.

FRITZ, J. C. The effect of feeding grit on digestibility in the domestic fowl. Poultry Science, Champaign, v. 16, n. 1, p. 75-79, Jan. 1937.

FRITZ, J. C.; BURROWS, W. H.; TITUS, H. W. Comparison of digestibility in gizzarde dectomized and normal fowl. Poultry Science, Champaign, v. 15, n. 3, p. 239-243, May 1936.

KENNARD, D. C.; CHAMBERLIN, V. D. Insoluble grit for chickens. Ohio: Agricultural Experiment Station, 1959. (Research Bulletin, 848).
McINTOSH, J. I.; SLINGER, S. J.; SIBBALD, I. R.; ASHTON, G. C. Factors affecting the metabolizable energy content of poultry feeds. 7. The effects of grinding, pelleting and grit feeding on the availability of the energy of wheat, corn, oats and barley. 8. A study on the effects of dietary balance. Poultry Science, Champaign, v. 41, n. 2, p. 445-456, Mar. 1962.

NIR, I.; MELCION, J. P.; PICARD, M. Effect of particle size of sorghum grains on feed intake and performance of young broilers. Poultry Science, Champaign, v. 69, n. 12 , p. $2177-2184$, Dec. 1990.

PORTELLA, F. J.; CASTON, L. J.; LEESON, S. Apparent feed particle size preference by broilers. Canadian Journal of Animal Science, Ottawa, v. 68, n. 3, p. $923-930$, Sept. 1988

REECE, F. N.; LOTT, B. D.; DEATON, J. W. The effects of hammer mill screen size on ground corn particle size, pellet durability, and broiler performance. Poultry Science, Champaign, v. 65, n. 7, p. 1257-1261, July 1986.

ROSTAGNO, H. S.; ALBINO, L. F. T.; DONZELE, J. L.; GOMES, P. C.; FERREIRA, A. S.; OLIVEIRA, R. F.; LOPES, D. C. Tabelas brasileiras para aves e suínos: composição de alimentos e exigências nutricionais. Viçosa: UFV, 2000. 141 p.

ZANOTTO, D. L.; MONTICELLI, C.; MAZZUCO, H. Implicações da granulometria de ingredientes de rações sobre a produção de suínos e aves. In: SIMPÓSIO LATINO-AMERICANO DE NUTRIÇÃO DE SUÍNOS E AVES, 1995, Campinas. Anais... Campinas: CBNA, 1995. p. 111-133. 